\title{
A PERCEPCÃO DOS PROFISSIONAIS DE CONTABILIDADE NO ÂMBITO DA PREFEITURA DO MUNICÍPIO DE SÃO PAULO, DE NECESSIDADES DE MUDANCAS NA LEI 4.320/64: SINTOMAS DA NECESSIDADE DE MUDANÇA
}

\author{
ACCOUNTING PROFESSIONALS PERCEPTIONS UNDER THE \\ MUNICIPAL GOVERNMENT OF SÃO PAULO, NECESSITIES FOR \\ CHANGING LAW 4320/64: SYMPTOMS OF NECESSITY FOR \\ CHANGING
}

Data do recebimento do artigo: 15/06/2013

Data do aceite do artigo: 09/09/2013

Data da publicação: 2/12/2013

\author{
Marília Cassia Teixeira ${ }^{1}$ \\ Graduado em Ciências Contábeis \\ Pontifícia Universidade Católica de São Paulo \\ Antonio Benedito da Silva Oliveira \\ Doutor em Ciências Contábeis \\ Professor do Mestrado em Ciências Contábeis \\ Pontifícia Universidade Católica de São Paulo
}

\section{RESUMO}

Neste trabalho de título a percepção dos profissionais de contabilidade no âmbito da Prefeitura do Município de São Paulo, das mudanças da Lei 4.320/64 e o impacto da Lei $101 / 00$, buscou-se alcançar o objetivo de captar a percepção dos profissionais de contabilidade no âmbito da Prefeitura do Município de São Paulo, das mudanças da Lei 4.320/64 e o impacto da Lei 101/00 e considerado o atual estado de harmonização das práticas contábeis do setor público. Neste contexto investigou-se a seguinte questão de pesquisa: Existe a necessidade de mudança na Lei 4320/64, na percepção dos técnicos, gestores e auditores do Tribunal de Contas do Município de São Paulo? A pesquisa foi realizada através da aplicação de um questionário a vinte e um profissionais de Contabilidade, do município com funções de gestão, de operação e auditores do tribunal de contas. Pelas respostas obtidas verificou-se que, na percepção destes indivíduos, a Lei 4.320/64 carece de atualização. Outros aspectos como a complexidade da lei em relação ao tamanho de muitos municípios foram levantados, bem como a necessidade de uma interpretação uniforme da Lei. Os conflitos entre a Lei 4.320/64 e a Lei Complementar 101/00 são resolvidos, seguindo o que estabelece a LC

\footnotetext{
${ }^{1}$ Autor para correspondência: Pontifícia Universidade Católica de São Paulo - R. Monte Alegre, 984 - Perdizes, São Paulo - SP,Brasil - 05014-901
} 
101/00, por ser mais recente. Foi colocado ainda que, na visão destes profissionais, a harmonização das práticas contábeis é inevitável também no setor público, posto o atual grau de globalização que vivemos.

Palavras-chaves: Lei 4.320/64; Harmonização das Práticas Contábeis; Setor Público; Lei 101/2000.

\begin{abstract}
This paper heading accounting professionals perceptions under the Municipal Government of São Paulo, changes of Law 4320/64 and impact of Law 101/00. We attempted to achieve the goal of capturing accounting professionals perceptions under the Municipal Government of São Paulo, changes of Law 4320/6, impact of Law 101/00 and being considered the current harmonization condition of accounting practices in public sector. This investigated connection follows the research question: Is there the necessity for changing the Law 4320/64, in technicians, managers and auditors perceptions of the Court Account in São Paulo? The research was performed over the questionnaire to twenty-one accounting professionals, the municipality with managerial functions, operating and auditors of the court accounts. By the answers obtained it was found that the perception of these individuals, the Law 4320/64 needs to be updated. Other aspects such as the complexity of the law regarding to the size of many districts were collected, and the necessity for a uniform interpretation of Law. The conflicts between the Law 4320/64 and the Supplementary Law 101/00 are solved, following which establishes LC 101/00, since it is more recent. It was further placed that in the view of these professionals, the harmonization of accounting practices is unavoidable as well as in the public sector, the present level of globalization we live.
\end{abstract}

Keywords: Law 4,320 / 64; Harmonization of Accounting Practices; Public Sector; law $101 / 2000$. 


\section{INTRODUÇÃO}

A atual Constituição em 1988, prevê em seu art. 165 a edição de uma Lei Complementar para substituir a Lei 4.320/64, que estabelece normas gerais de Direito Financeiro para elaboração e controle dos orçamentos e balanços da União, dos Estados, dos Municípios e do Distrito Federal.

A Lei 4.320/64 representa um marco normativo na Contabilidade Pública Brasileira. E considerando a época em que foi editada a Lei apresenta-se ainda bastante atual. No entanto, considerando-se as mudanças no ambiente sócio-cultural-político e econômico brasileiro, a referida Lei está desatualizada.

Em 2000, Lei Complementar 101 publicada em 04 de maio de 2000, estabeleceu normas de finanças públicas voltadas para a responsabilidade na gestão fiscal, nos três âmbitos da Administração Publica, União, Estado e Município, e em alguns de seus artigos concorre com o estabelecido na Lei 4.320/64. Com esse conflito, geraram-se discussões e debates sobre a contabilidade pública no que tange a a aspectos de elaboração, execução orçamentária e controle.

Este trabalho teve por objetivo captar a percepção dos profissionais de contabilidade no âmbito da Prefeitura do Município de São Paulo, das mudanças da Lei 4.320/64 e o impacto da Lei 101/00 e considerado o atual estado de harmonização das práticas contábeis do setor público, foi averiguado o reflexo desta questão no âmbito do Município de São Paulo. E investigou-se a seguinte questão de pesquisa: Existe a necessidade de mudança na Lei 4320/64, na percepção dos técnicos, gestores e auditores do Tribunal de Contas do Município de São Paulo?

\section{DESCRIÇÃO DA PESQUISA E DA METODOLOGIA}

A pesquisa foi realizada por meio da aplicação de um questionário a vinte e um profissionais de Contabilidade, do município. O nosso espaço amostral é composto por três grupos: Gestores, aqueles com poder de decisão, em cargos de chefia ou supervisão, nossa amostra deste grupo foi composta por cinco indivíduos; o segundo grupo do espaço amostral compõe-se de profissionais da área operacional, sem poder de decisão. Nossa amostra deste grupo foi de quinze indivíduos. O terceiro grupo do espaço amostral estudado seria o composto por profissionais do T.C.M.S.P. - Tribunal de Contas do Município de São Paulo. Deste grupo obteve-se uma amostra de dois indivíduos.

O questionário foi composto por um preâmbulo que informando ao respondente a finalidade do questionário. A seguir foi solicitado a função e lotação do respondente, para enquadrá-lo nos grupos respectivos, e algumas outras questões demográficas, como formação, tempo decorrido desde a titulação, tempo de experiência no cargo e na Prefeitura de São Paulo.

A nossa amostragem foi feita por conveniência, a seleção dos respondentes foi realizada através de indicações de supervisões e chefes de setores municipais, que consideramos estratégicos: Contadoria Municipal, Tesouro, Tribunal de Contas, Ouvidoria, 
Secretaria das Finanças, Secretária do Governo e Secretária Municipal de Participação e Parceria.

Assim, o questionário foi composto por dez perguntas: as cinco primeiras questões são para averiguar a experiência do respondente no seu órgão de lotação, tanto como contador quanto como servidor/colaborador municipal, contemplando também uma descrição das suas atividades.

As outras cinco, abordaram questões específicas sobre o tema, ancoradas em pontos ressaltados na literatura, todas abertas, conforme quadro a seguir.

\begin{tabular}{|c|c|c|c|}
\hline Questão & Informação esperada & $\begin{array}{l}\text { Relação com o } \\
\text { objetivo da } \\
\text { pesquisa }\end{array}$ & $\begin{array}{l}\text { Referencial } \\
\text { Teórico }\end{array}$ \\
\hline $\begin{array}{l}\text { Quais as dificuldades } \\
\text { encontradas na aplicação da Lei } \\
\text { 4.320/64, no município? }\end{array}$ & $\begin{array}{l}\text { Dificuldades } \\
\text { apresentadas na } \\
\text { execução da Lei } \\
4.320 / 64\end{array}$ & $\begin{array}{l}\text { Aplicabilidade da } \\
\text { Lei } 4.320 / 64 \text { no } \\
\text { município }\end{array}$ & $\begin{array}{l}\text { Silva (2009), } \\
\text { Pigatto (2004) }\end{array}$ \\
\hline $\begin{array}{l}\text { Tendo vista a realidade } \\
\text { municipal, você teria alguma } \\
\text { sugestão de mudança para a Lei } \\
4.320 / 64 ?\end{array}$ & $\begin{array}{l}\text { Demanda para a Lei } \\
\text { Complementar na } \\
\text { visão municipal }\end{array}$ & $\begin{array}{l}\text { Necessidades a } \\
\text { serem } \\
\text { contempladas pela } \\
\text { lei complementar }\end{array}$ & $\begin{array}{l}\text { Pigatto (2004), } \\
\text { Nascimento (2007) }\end{array}$ \\
\hline $\begin{array}{l}\text { Em sua opinião, a publicação de } \\
\text { LRF gerou necessidades de } \\
\text { alteração na Lei } 4.320 / 64 \text { ? }\end{array}$ & $\begin{array}{l}\text { Aplicabilidade em } \\
\text { conjunto da LRF e a } \\
\text { Lei } 4.320 / 64\end{array}$ & $\begin{array}{l}\text { Harmonização com } \\
\text { a LRF }\end{array}$ & $\begin{array}{l}\text { Silva (2009, } \\
\text { Nascimento (2007) }\end{array}$ \\
\hline $\begin{array}{l}\text { A Constituição } 1988 \text { prevê } \\
\text { publicação da Lei Complementar } \\
\text { que substituirá a Lei } 4.320 / 64 \text {, } \\
\text { mas ainda não foi editada. Você } \\
\text { sente a necessidade dessa } \\
\text { publicação? Por quê? }\end{array}$ & $\begin{array}{l}\text { Considerações sobre os } \\
\text { profissionais atuantes } \\
\text { na área se na pratica há } \\
\text { necessidade }\end{array}$ & $\begin{array}{l}\text { Verificação sobre a } \\
\text { Urgência, ou não, } \\
\text { na edição da Lei } \\
\text { Complementar }\end{array}$ & $\begin{array}{l}\text { Silva (2009), } \\
\text { Pigatto (2004), } \\
\text { Nascimento (2007) }\end{array}$ \\
\hline $\begin{array}{l}\text { Considerando o atual movimento } \\
\text { de unificação das práticas } \\
\text { contábeis no Brasil e } \\
\text { internacionais, você acha a Lei } \\
4.320 / 64 \text { coerente com as } \\
\text { práticas internacionais? Caso } \\
\text { não, quais seriam as principais } \\
\text { modificações necessárias? }\end{array}$ & $\begin{array}{l}\text { Se o movimento de } \\
\text { unificação das } \\
\text { praticadas contábeis } \\
\text { internacionais } \\
\text { influenciará a Lei } \\
\text { complementar a ser } \\
\text { editada }\end{array}$ & $\begin{array}{l}\text { Relação com o } \\
\text { movimento de } \\
\text { unificação das } \\
\text { praticadas } \\
\text { contábeis. }\end{array}$ & $\begin{array}{l}\text { Macêdo (2003), } \\
\text { Carlin (2008) }\end{array}$ \\
\hline
\end{tabular}

Quadro 1: Questões temáticas do questionário e sua relação com o referencial teórico.

Fonte: elaborado pelos autores, 2013.

Como o questionário foi estruturado com a utilização de questões abertas, com uma exceção, seu estudo foi feito através uma análise de conteúdo.

Conforme Moraes (1999): 
A análise de conteúdo constitui uma metodologia de pesquisa usada para descrever e interpretar o conteúdo de toda classe de documentos e textos. Essa análise, conduzindo a descrições sistemáticas, qualitativas ou quantitativas, ajuda a reinterpretar as mensagens e a atingir uma compreensão de seus significados num nível que vai além de uma leitura comum.

Esta técnica conforme Bardin (2004), tem a finalidade de evidenciar idéias e fatos implícitos em textos e documentos. Um aspecto fundamental é a classificação desses conteúdos implícitos em categorias de interesse. Essas categorias podem ser obtidas à partir da teoria, ou, podem ser descobertas à partir de uma análise preliminar das respostas obtidas.

Criou-se neste estudo o constructo de sintomas, agrupados em três grandes classes: sintomas que remetiam a problemas quanto à atualização da Lei 4.320/64; sintomas que remetiam a dificuldades oriundas de uma complexidade percebida pelos respondentes, na Lei 4.320/64; e sintomas que remetiam a aspectos econômico-financeiros relacionados à sua aplicação.

\section{REVISÃO DA LITERATURA}

Nos últimos anos, debates recorrentes têm ocorrido sobre a necessidade ou não da reformulação da Lei 4.320/64, principalmente após a aprovação das Normas Brasileiras de Contabilidade aplicadas ao setor público por Resoluções do Conselho Federal de Contabilidade.

Algumas alegações são de origem constitucional, e surgem a partir da idéia de que com a Constituição de 1988 é preciso aguardar a Lei Complementar que substituirá a Lei 4.320/64, como relata (Silva, 2009).

O autor defende a idéia que a Lei $4.320 / 64$ precisa ser estudada com base nos dispositivos da Constituição de 1988 para identificar dispositivos que na lição de Celso Ribeiro Bastos, extraído do artigo acima referenciado, estejam a

\footnotetext{
... esbarrar com o texto constitucional, quer na sua literalidade, nos seus princípios, nos seus valores, ou quer, ainda, nas disposições programáticas - em quaisquer dessas hipóteses, a norma não transpõe os obstáculos para sua recepção e torna-se também uma norma destituída de eficácia e que acompanha a revogação por que passou a Constituição anterior... Silva (2009, p. 1).
}

O Legislador Constitucional somente tratou dos instrumentos de planejamento (Plano Plurianual, Lei de Diretrizes Orçamentárias e Lei Orçamentária Anual) e de normas de gestão financeira e patrimonial que dizem respeito à forma de administração dos recursos e deixou a regulamentação da matéria para a legislação ordinária. 
Esta linha é bem clara, pois se está prevista a edição da Lei Complementar, não cabe discussão sobre sua publicação, mas sim, discutirmos os aspectos que podem ser incluídos nesta Lei para que ela atenda as necessidades do setor público.

Nascimento (2007, p. 2), afirma que:

\begin{abstract}
a necessária revisão dos preceitos vigentes em face das demandas de informações e do esforço de harmonização nacional e internacional se dá pela busca de uma sólida base teórica que embase a reforma das práticas vigentes e oriente a mudança da legislação quanto as normas gerais de direito financeiro no que tange à contabilidade governamental.
\end{abstract}

Isto foi feito por meio da comparação das regras atualmente praticadas no Brasil e das praticadas no âmbito Internacional, com a formação de um Grupo de Trabalho envolvendo o CFC - Conselho Federal de Contabilidade e o Governo Federal

Um dos aspectos abordados pelo autor é o Regime Contábil misto adotado pelo setor público brasileiro (Regime de caixa para as Receitas e Regime de Competência para as Despesas), o autor relata, após uma longa análise que:

É adequado que as entidades do setor público adotem o regime de competência integral, por ser o mais difundido e o que reflete melhor a situação patrimonial e financeira da entidade, além de evitar distorções estatísticas e erros de interpretação das finanças públicas. (Nascimento, 2007, p. 59).

Este aspecto destacado pelo autor é um dos pontos mais polêmicos da Lei 4.320/64, pois é um ponto em que a Contabilidade Orçamentária se choca com a Contabilidade empresarial brasileira, a qual já adota o regime de competência.

Pigatto (2004), em sua Dissertação de Mestrado, também faz a discussão sobre a harmonização dos procedimentos contábeis brasileiros e internacionais, através de um estudo histórico-cultural comparativo entre a Contabilidade brasileira e a Contabilidade Internacional.

O autor relata os avanços das políticas públicas das últimas décadas, e como estes avanços influenciaram na administração pública e por conseqüência a Contabilidade Pública.

A problematização apresentada por Pigatto (2004) se refere à adoção do regime de competência para o setor público. $\mathrm{O}$ autor conclui que um dos únicos pontos de convergência entre os regimes contábeis, brasileiro e internacional, deva ser este. Os demais aspectos são de cunho cultural e histórico.

Nos países com origem contábil cameral da vertente germânica, bem como nos países de origem britânica e nos Estados Unidos a 
representação integrada do patrimônio ou dos recursos operacionais do governo é uma novidade que tem sido enfatizada nos seus processos reformistas. O método adotado tem sido o uso do regime de competência, porém o consenso termina nesse ponto. As divergências entre modelos dizem respeito ao escopo de utilização do princípio da oportunidade para então levar as variações registradas ao resultado de um período. A maior ou menor observância do princípio da oportunidade pode fazer com que se verifiquem diferenças significativas nas práticas contábeis comparadas entre um e outro país ou mesmo dentro de um determinado país como no caso dos Estados Unidos onde determinados fundos obedecem a um regime de competência fraco enquanto outros obedecem a um regime semi-forte ou forte. Assim, frente à diversidade contábil a normatização pretendida por órgãos como IFAC e FIJI, pode se constituir em um grande desafio. Pigatto (2004, p. 164)

Por outro lado, Carlin (2008), em artigo mais recente, aborda o tema de uma maneira mais pragmática, fazendo uma elação entre o processo de convergência e a edição da Lei complementar que substituirá a Lei 4.320/64 e a edição das Normas Contábeis para o Setor Público.

Este relato traz as dificuldades da harmonização contábil, porém temos que considerar que em um mundo globalizado onde desde países até municípios pequenos necessitam de recursos internacionais, esta harmonização é inevitável.

No caso brasileiro a questão do equilíbrio fiscal fez com que a grande preocupação dos legisladores recaísse sobre a limitação dos gastos dos governantes, culminando com a edição de Lei Complementar nº101/2000 conhecida como lei de Responsabilidade Fiscal.

A sociedade questiona incessantemente o fato de as receitas aumentarem e os serviços prestados à sociedade diminuírem ou no máximo permanecerem constantes, como relata Gimenes (2003).

Considerando que o trabalho visou abordar a percepção do contador público, consideramos pertinente referenciar a citação abaixo:

\footnotetext{
...um dos fatores que atribuem maior status a qualquer profissão é o nível de complexidade expressa nas suas atividades. Obviamente as normas internacionais trazem consigo um elevado grau de complexidade em função de aspectos subjetivos que envolvem o julgamento dos contadores. Essa subjetividade pode contribuir para a elevação da profissão contábil no Brasil. Pohlman e Alves (citado por Carlin, 2008, p. 7).
}

Esta afirmação induz a conclusão que na atualidade o profissional de Contabilidade tem que ter um perfil mais específico.

Dalfovo e Maçaneiro (2008) em trabalho intitulado "Contabilidade Pública: Limites e Possibilidade do Contador" relacionam as dificuldades destes profissionais a três variáveis: baixo nível Profissional, a ausência deste profissional na elaboração de softwares 
característicos do setor e por último a pouca mão de obra qualificada de técnicos no setor de informática para desenvolver sistemas contábeis adequados.

Este trabalho aborda o tema tecnológico em que o contador moderno está inserido. Hoje, na era da informação todos os usuários da contabilidade: população, fornecedores, agentes públicos querem os resultados rapidamente, porém os contadores, muitas vezes, são reféns de sistemas de informações falhos, os quais não foram planejados com um suporte legal e contábil adequado.

\section{APRESENTAÇÃO E ANÁLISE DOS DADOS}

As questões cujas respostas foram categorizadas - ou seja, distribuídas nas categorias de interesse - foram apresentadas no quadro 1.

A categorização das respostas foi apresentada no quadro 4. Neste quadro procurou-se aglutinar as respostas por semelhança contextual. Esta semelhança serviu como indicador das categorias, eixos, em torno das quais organizar as respostas.

O questionário utilizado dividiu-se em duas partes, na primeira delas, abrangendo cinco questões se buscou definir demograficamente a amostra. Essas questões demográficas estão apresentadas no quadro 2 .

1. É técnico em contabilidade ou bacharel?

2. Há quanto tempo?

3. Cargo ocupado?

3.2. Gestor ( )

3.3. Operacional ( )

4. Há quanto tempo exerce esta função?

5. Há quanto tempo trabalha na PMSP?

Quadro 2: Questões demográficas.

Fonte: elaborado pelos autores, 2013.

Nos quadros 3 e 4 é apresentada uma compilação das respostas obtidas, quanto às questões demográficas, sem nenhum tratamento. Elaborou-se o perfil demográfico da amostra neste quadro. 


\begin{tabular}{|l|r|}
\hline Respostas & Frequência das Respostas \\
\hline Questão 1 & 18 \\
\hline Bacharel & 3 \\
\hline Técnico em Contabilidade & 3 \\
\hline Questão 2 & 11 \\
\hline Menos de 10 anos & 5 \\
\hline De 11 a 20 anos & 2 \\
\hline De 21 a 30 anos & \\
\hline Mais de 30 anos & \\
\hline
\end{tabular}

Quadro 2: Questões 1 e 2.

Fonte: elaborado pelos autores, 2013.

\begin{tabular}{|l|r|}
\hline Respostas & Freqüência das Respostas \\
\hline Questão 3 & 11 \\
\hline Gestor & 8 \\
\hline Não Gestor & 2 \\
\hline TCM/SP & \\
\hline Questão 4 & 11 \\
\hline Menos de 10 anos & 5 \\
\hline De 11 a 20 anos & 4 \\
\hline De 21 a 30 anos & 1 \\
\hline Mais de 30 anos & \\
\hline
\end{tabular}

Quadro 3: Questões 3 e 4.

Fonte: elaborado pelos autores, 2013.

\section{Questão 1}

Em relação à questão 1, que investigou a formação profissional dos respondentes, verificou-se que esse grupo compõe-se $86 \%$ de Bacharéis e $14 \%$ de técnicos em contabilidade. 


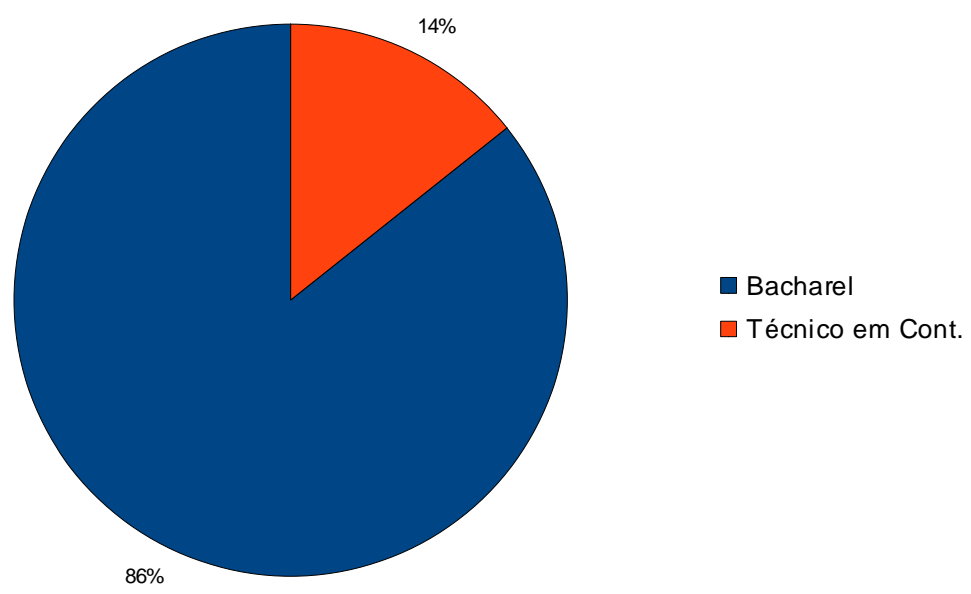

Gráfico 1: Formação Profissional dos respondentes.

Fonte: elaborado pelos autores, 2013.

É de interesse que se note a participação proporcionalmente maior dos bacharéis em relação aos profissionais com o grau de técnico apenas. Considerando-se apenas este dado espera-se um elevado nível de atuação profissional, competência técnica e postura crítica destes profissionais.

\section{Questão 3}

A questão três se referia à atuação profissional dos respondentes junto à prefeitura. Buscou-se enquadrar os respondentes em três grandes grupos: a) gestores: responsáveis por áreas e pessoas; b) não gestores: técnicos responsáveis pela execução de tarefas; e c) técnicos do TCM/SP.

E sua totalidade a amostra é composta por $52 \%$ de gestores, $38 \%$ de não gestores e $10 \%$ de respondentes do TCM/SP 


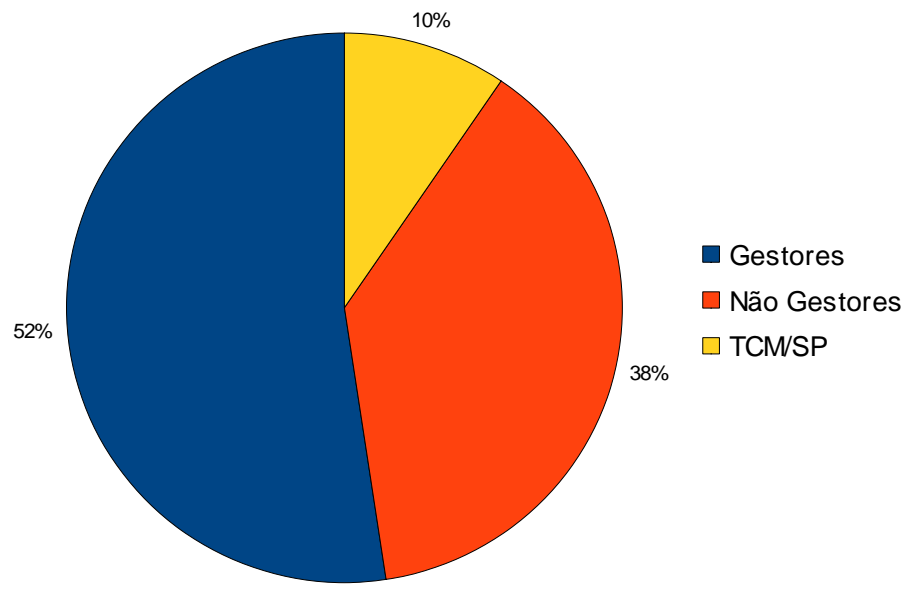

Gráfico 2: Atuação profissional dos respondentes.

Fonte: elaborado pelos autores, 2013.

Para a amostra foram distribuídos questionários no âmbito da Prefeitura do Município de São Paulo em diversos Órgãos e Secretarias: TCM/SP, Ouvidoria, Tesouro Municipal, Secretaria das Finanças, Secretaria Municipal de Participação de Parceria, Secretaria Municipal da Cultura, Departamento de Contadoria do Município, Secretaria Municipal do Governo, obteve-se um número maior de respostas dos gestores devido a resistências de alguns profissionais em funções operacionais em responder os questionários. 
Questões 2, 4 e 5

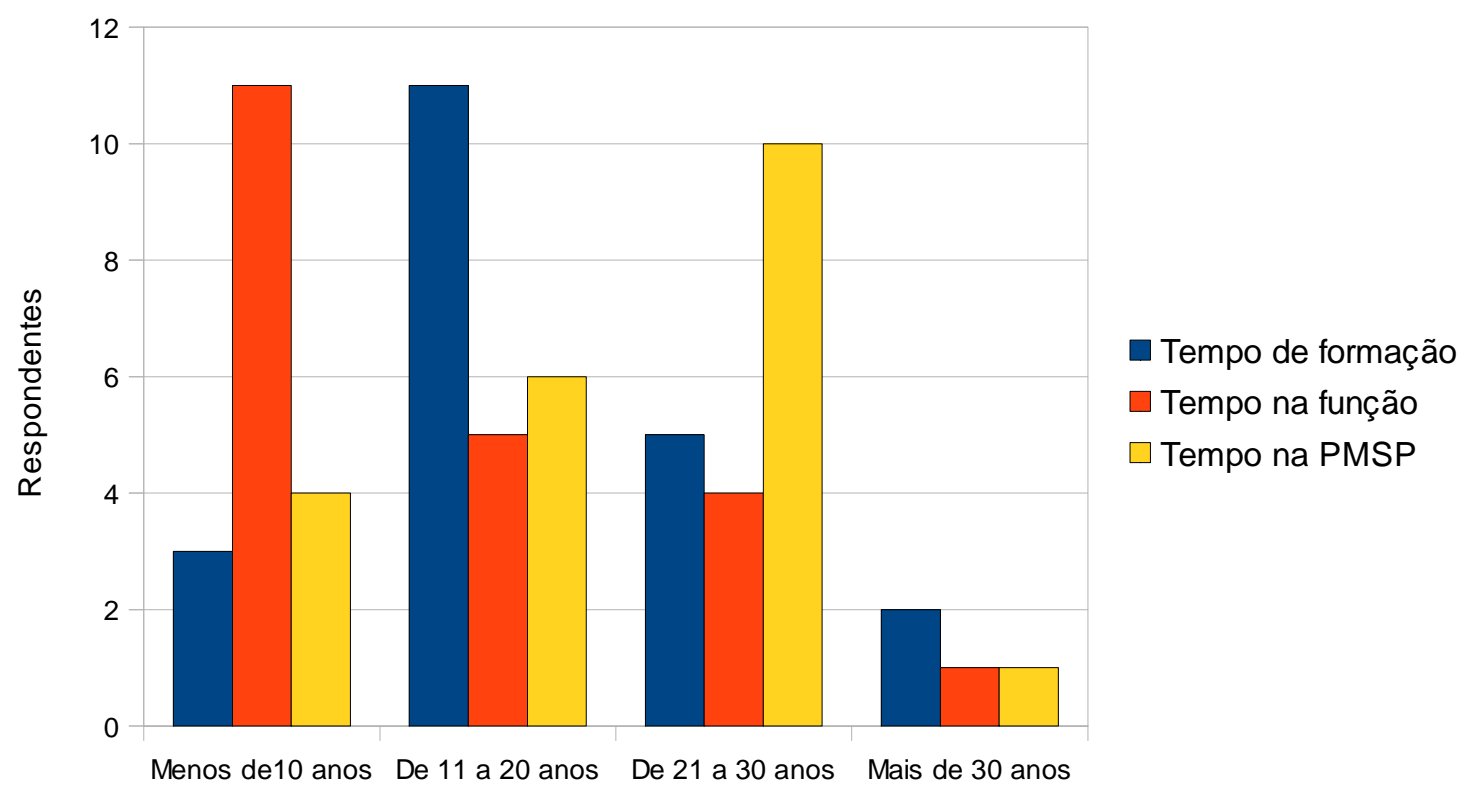

Gráfico 3: Tempo de atuação.

Fonte: elaborado pelos autores, 2013.

Os profissionais componentes da amostra, em sua maioria, tem de 11 a 20 anos de formação, já em relação ao tempo de Prefeitura, caracteriza-se por profissionais com um tempo entre 21 a 30 anos e com menos de 10 anos na função.

\begin{tabular}{|l|r|}
\hline Respostas & Frequência das Respostas \\
\hline Questão 5 & 4 \\
\hline Menos de 10 anos & 6 \\
\hline De 11 a 20 anos & 10 \\
\hline De 21 a 30 anos & 1 \\
\hline Mais de 30 anos & \\
\hline
\end{tabular}

Quadro 4: Questão 5.

Fonte: elaborado pelos autores, 2013. 


\section{Análise das respostas temáticas: 6, 7, 8, 9 e 10.}

Após um estudo preliminar das respostas obtidas às questões temáticas, apresentadas no quadro 1, foram determinadas freqüências do aparecimento de termos, conceitos, ou, afirmações, configurando o que se denominou no âmbito deste trabalho de sintomas. Esses sintomas são evidências na forma de indicadores de uma situação diagnosticada no contexto da gestão pública quanto à necessidade, ou, não, de modificações na prática contábil, conforme inclusive previsto no artigo 165 da Constituição Federal de 1988. Por exemplo, como um sintoma da necessidade de atualização, utilizou-se a afirmação de um respondente com o cargo de Direção Técnica de Contabilidade que afirma: " Ela é muito antiga, deveria ser adequada aos dias atuais". Respostas deste tipo foram agrupadas, compondo o sintoma "Desatualização e necessidade de atualização".

Note-se que respostas que demonstram um alheamento do problema, ou, uma vontade de não se envolver em sua discussão, algumas vezes observadas nesse estudo, são também sintomas que surgem da especialização dos funcionários em suas várias atividades, rotinas de trabalho e, talvez, também de aspectos culturais. Este fato observado configura um aspecto merecedor de atenção uma vez que no contexto atual, as normas internacionais, conforme já exposto trazem um grau maior de complexidade, pelos aspectos subjetivos e necessidade de julgamento por parte do contador. Esses aspectos contribuirão para a valorização do contador público na sociedade, conforme Carlin (2008,p.7); no entanto, exigirão desse profissional um grande esforço no acompanhamento e adequação à esta nova realidade.

No quadro 5, são apresentados então os sintomas observados e sua frequiência nos quadros 6 e 7 . 


\begin{tabular}{|l|r|}
\hline Sintomas observados de acordo com as questões & Frequência das Respostas \\
\hline Questão 6 & 3 \\
\hline Não Aplicação, na integra pelos gestores. & 3 \\
\hline Referência ao tamanho do Município & 3 \\
\hline Desatualizada/necessidade de Atualização & 5 \\
\hline Não sente dificuldade & 2 \\
\hline Sem resposta & 7 \\
\hline Outras & 3 \\
\hline Questão 7 & 2 \\
\hline Não. & 4 \\
\hline Faz referência a Restos a pagar & 1 \\
\hline Atualização & 3 \\
\hline Dar ênfase aos Custos dos serviços prestados & 1 \\
\hline Faz referência ao tamanho do Município & 2 \\
\hline Distorção na gestão de recurso: enfoque no orçamento & 1 \\
em prejuízo ao enfoque patrimonial & 6 \\
\hline Adaptar à Lei das S/A / Contabilidade Privada & \\
\hline Sem resposta & 13 \\
\hline Outras & 7 \\
\hline Questão 8 & 1 \\
\hline Sim & \\
\hline Não & \\
\hline Sem resposta & \\
\hline Q & \\
\hline
\end{tabular}

Quadro 6: Questões 6 e 7.

Fonte: elaborado pelos autores, 2013. 


\begin{tabular}{|l|r|}
\hline Sintomas observados de acordo com as questões & Frequência das Respostas \\
\hline Questão 9 & 13 \\
\hline Sim & 1 \\
\hline Não & 1 \\
\hline Como está previsto na Constituição não cabe discussão. & 1 \\
\hline Depende do que contém esta Lei Complementar. & 1 \\
\hline Faz referencia aos projetos que estão em tramitação e as & 1 \\
NBC's para o Setor Público & 1 \\
\hline O balanço de 2008 obedeceu as diretrizes contábeis: & 1 \\
STN/SOF e MPS. & 1 \\
\hline Entende que a nova Lei servirá para dirimir as NBC's & 7 \\
para o Setor Público & 5 \\
\hline Urgente & 7 \\
\hline Sem resposta & 1 \\
\hline Questão 10 & 1 \\
\hline Não. & \\
\hline Não conhece as normas internacionais & \\
\hline Sim & \\
\hline Já está acontecendo & \\
\hline Sem resposta & \\
\hline
\end{tabular}

Quadro7: Questões 9 e 10.

Fonte: elaborado pelos autores, 2013.

Na questão 6, observa-se que os respondentes que não tem dificuldades na aplicação da Lei 4.320/64 são 5 (cinco).

Os que afirmam que tem alguma dificuldade relatam vários fatores: desatualização da Lei, tamanho do Município, a não aplicação da Lei pelos gestores, ou seja, há uma gama de fatores que interferem na aplicação da Lei que serão abordados mais à frente.

$\mathrm{Na}$ a questão 7, buscou-se obter sugestões para a nova Lei. Destacam-se: a resolução da problemática dos Restos a Pagar, a possibilidade de tratamento diferenciado para Municípios de grande complexidade, como é o caso de São Paulo e a desatualização da Lei simplesmente.

Na questão 8, que aborda se a Lei Complementar 101/00, interferiu na aplicação da Lei 4.320/64, a maioria, onze respondentes afirmaram que houve interferência.

Na questão 9, todos avaliam como necessária a edição da Lei Complementar. Seja por aspectos jurídicos como: "está previsto na Constituição que a Lei Complementar substituirá a Lei 4.320/64, não há como ser questionada. Ela deve ser respeitada e concretizada.”. Ou, por questões como necessidade de atualização: "Sim; para abarcar a realidade atual,"

$\mathrm{Na}$ questão 10, que aborda a harmonização das normas contábeis brasileiras e internacionais, observou-se que alguns respondentes não conhecem as normas internacionais, totalizando cinco respondentes; dentre dos que conhecem, oito consideram que deve haver a 
harmonização. Dentre os favoráveis a harmonização surgiram argumentações como a de que é necessário o "Enfoque patrimonial nas contas públicas"; e que existe a necessidade de se " Adequar as Normas Internacionais padronizadas." Pois, em que pese a importância da Lei 4.320/64, que, nas palavras de um dos respondentes, é:

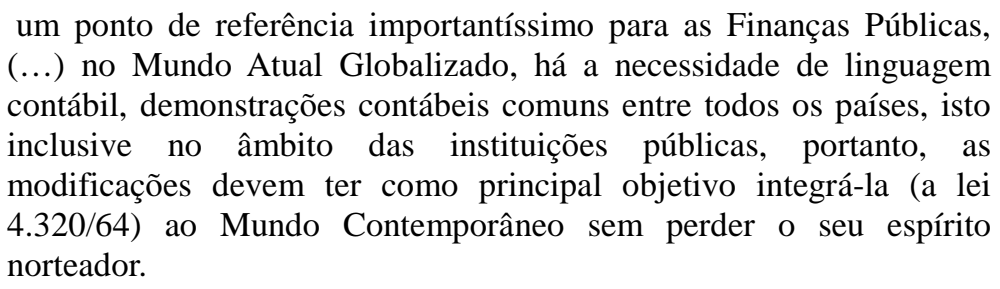

Note-se que de vinte e um respondentes, quinze sentiram aptos a opinar. Nove deles favoravelmente à necessidade de harmonização e seis desfavoravelmente.

O grupo do TCMSP, respondeu as perguntas com a perceptiva de auditores, ou seja, apontando as falhas encontradas em suas auditorias.

\begin{tabular}{|l|l|l|}
\hline \multicolumn{3}{|c|}{ Categorias de Sintomas para Classificação das Respostas Obtidas } \\
\hline $\begin{array}{l}\text { Sintomas relativos à } \\
\text { complexidade }\end{array}$ & $\begin{array}{l}\text { Sintomas relativos à } \\
\text { necessidade de atualização }\end{array}$ & $\begin{array}{l}\text { Sintomas que referenciam } \\
\text { aspectos financeiros } \boldsymbol{e} \\
\text { econômicos }\end{array}$ \\
\hline Tamanho do Município & Desatualizada & Gestão de recursos \\
\hline $\begin{array}{l}\text { Aplicabilidade na íntegra } \\
\text { pelos Gestores }\end{array}$ & $\begin{array}{l}\text { Harmonização com normas } \\
\text { internacionais }\end{array}$ & Tratamentos "Restos a Pagar" \\
\hline $\begin{array}{l}\text { planejamento financeiro e } \\
\text { orçamentário }\end{array}$ & $\begin{array}{l}\text { Adequar à nova realidade } \\
\text { social do país e internacional }\end{array}$ & $\begin{array}{l}\text { Enfase aos custos dos } \\
\text { serviços }\end{array}$ \\
\hline $\begin{array}{l}\text { Aproximá-la ao máximo da } \\
\text { contabilidade privada }\end{array}$ & Regime de competência \\
\hline & & $\begin{array}{l}\text { Controle de bens patrimoniais } \\
\text { móveis. }\end{array}$ \\
\hline & $\begin{array}{l}\text { Depreciação do Ativo } \\
\text { Permanente }\end{array}$ \\
\hline & Enfoque patrimonial \\
\hline
\end{tabular}

Quadro7: Categorização das respostas.

Fonte: elaborado pelos autores, 2013. 


\section{CONCLUSÃO}

Em relação aos objetivos declarados, observou-se pelas respostas que os contadores tinham muito a contribuir na questão da aplicabilidade da Lei 4.320/64, apontando os pontos críticos de desatualização da Lei e muitos dos seus pontos positivos.

Os respondentes agregaram sugestões importantes, como a possibilidade da aplicação da Lei considerando o tamanho e a complexidade dos Municípios.

Estes respondentes também apontaram a importância da Lei de Responsabilidade Fiscal para o controle dos gastos públicos e o cuidado da coisa pública, mas neste item indicaram a dificuldade de atender este preceito legal naquilo que conflita com a Lei 4.320/64.

A convergência com as normas internacionais para a maioria realmente é inevitável, considerando o mundo globalizado que vivemos hoje. No entanto, novas pesquisas seriam necessárias para que se conclua quanto a problemas conceituais e operacionais relacionados a este processo de harmonização.

A contribuição deste trabalho é no sentido de que em muitos casos a mudança de uma Lei ou norma deve ter a contribuição dos indivíduos que as aplicam no seu dia-a-dia,, pois estes tem percepções quanto a necessidade e os reflexos dessas mudanças.

\section{REFERÊNCIAS}

BRASIL. Lei Federal nº 4.320 de 17 de março de 1964. Estatui Normas Gerais de Direito Financeiro para elaboração e controle dos orçamentos e balanços da União, dos Estados, dos Municípios e do Distrito Federal.

Lei Complementar 101 de 4 de maio de 2000, Estabelece normas de finanças públicas voltadas para a responsabilidade na gestão fiscal e dá outras providências.

Lei Federal 8.666 de 21 de junho de 1993, Regulamenta o art. 37, inciso XXI, da Constituição Federal, institui normas para licitações e contratos da Administração Pública e dá outras providências.

Lei Federal 11.638 de 28 de dezembro de 2007, Altera e revoga dispositivos da Lei no 6.404, de 15 de dezembro de 1976, e da Lei no 6.385 de 7 de dezembro de 1976, e estende às sociedades de grande porte disposições relativas à elaboração e divulgação de demonstrações financeiras.

CARLIN, Diego de O. Considerações Sobre o Processo de Convergência na Contabilidade Pública Brasileira, Revista CRCRS, v. 8 setembro de 2008 
CONSELHO FEDERAL DE CONTABILIDADE. Resolução CFC 1.111 de 29/11/ 2007.

DALFOVO, Oscar; Maçeneiiro Wanderley. Contabilidade Pública: Limites e Possibilidade do Contador Revista Interdisciplinar Cientista Aplicada - Blumenau v.2 n. 1, p. 01-14, Sem. I, 2008

DI PIETRO, Maria Sylvia Zanella. Direito administrativo. 12. ed. São Paulo/SP: Atlas, 2000.

GIMENES, Daniela. A. Avaliação de Desempenho do Setor Público, Monografia desenvolvida em cumprimento à exigência curricular do Curso de Ciências Contábeis da UNIMEP, sob orientação do Prof ${ }^{\text {o: }}$ Luiz Antonio Arthuso, Piracicaba, dezembro de 2003

MACÊDO, Maurício Ferreira de. Impacto das Normas Internacionais de Contabilidade na Apresentação das Demonstrações Contábeis. Revista Brasileira de Contabilidade. Conselho Federal de Contabilidade, 2003.

MORAES, Alexandre. Direito Constitucional 1. ed. São Paulo/SP: Atlas, 2000.

NASCIMENTO, Edson Ronaldo \& Debus Ilvo. Entendendo a Lei de Responsabilidade Fiscal, Brasilia, Abril de 2001.

NASCIMENTO, Leonardo S. do. A Reforma da Contabilidade Governamental Brasileira: a necessária revisão dos preceitos vigentes em face das demandas de informações e do esforço de harmonização nacional e internacional. Brasília: ESAF, 2007.

PIGATTO, José A. M. Estudo Comparativo dos Regimes Contábeis Governamentais. 2004, 198 p. Dissertação de Mestrado - Faculdade de Economia, Administração e Contabilidade, Universidade de São Paulo.

SILVA, Lino Martins. A NOVA CONTABILIDADE PUBLICA: patologia dos balanços. http://linomartins.wordpress.com/2009/03/28/a-nova-contabilidade-publica-patologia, acesso em 28/03/2009

MORAES, Roque. Análise de conteúdo. Revista Educação, Porto Alegre, v. 22, n. 37, p. 732, 1999. Disponível no endereço eletrônico: http://cliente.argo.com.br/ mgos/analise_de_conteudo_moraes.html Acesso em setembro de 2010.

BARDIN, L. Análise de Conteúdo. 3ª Ed. Lisboa: Edições 70, 2004. 